\title{
Use of an open access spirometry service by general practitioners
}

\author{
Heidi Wolfenden ${ }^{a}$, Lorna Bailey ${ }^{a}$, Kevin Murphy ${ }^{a}$, \\ Martyn R. Partridge ${ }^{\text {b,* }}$
}

\author{
a Department of Respiratory Medicine, Charing Cross Hospital, London, UK \\ b Imperial College London, NHLI Division at Charing Cross Hospital, London W6 8RP, UK
}

Received 9 November 2005; accepted 22 May 2006

\begin{abstract}
KEYWORDS
Spirometry;

Primary care;

Asthma;

Chronic obstructive

pulmonary disease;

Obesit

\section{Summary}

Aims: To understand better which patients with wich dianoses or suspected diagnoses are referred for spirometry in privasy care, and to assess whether all such referrals are apnroplate.

Methods: ?ou con seclutive patient referralst $\mathrm{can}$ open access spirometry service tran tenccal general practicos veie eluated by perusing the request forms, and analysis of the srirore ly revilis and the report sent to the general practitioner (GP):

est: ts: $51 \%$ of all referrals had suspected or stated COPD, but airway obstruction was demonstrated in only $53 \%$ of cases. A minority had a degree of reversibility which suggested an additional asthma component at least. Airway obstruction was rarely demonstrated in patients referred with stated or suspected asthma. 117 patients were referred with stated or suspected airway disease but had no evidence of airway narrowing on testing. $14.5 \%$ of these had an unexpected small lung (restrictive) disorder. Six of these had a BMI of more than 30 .

Conclusion: Most referrals with stated or suspected COPD were highly appropriate since spirometry is required in order to establish the correct diagnosis. Referral of patients with suspected asthma is less likely to be helpful, and a period of home peak flow monitoring may be more useful. Restrictive disorders can be confused with airway disorders, and obesity may be underestimated as a cause of breathlessness. (c) 2006 General Practice Airways Group. Published by Elsevier Ltd. All rights reserved.
\end{abstract}

\footnotetext{
* Corresponding author. Tel.: +44 208846 7587; fax: +44 2088467999.

E-mail address: m.partridge@imperial.ac.uk (M.R. Partridge).
}

\section{Introduction}

There are over 30 common lung diseases and many of these share symptoms such as breathlessness with disorders of other systems - for example, heart disease, anaemia and obesity. 
The common lung diseases need to be correctly differentiated. Clinical history, examination and chest radiography may aid differentiation and correct diagnosis. Spirometry is of value in the differentiation of airway disorders from small lung disorders and also in the assessment of severity.

Spirometry has been taught to generations of medical students, often during pre-clinical physiology classes, and its use appears prominently in guidelines for the management of lung disease. It also features in the Quality Outcomes Framework (QOF) criteria for the management of patients with chronic obstructive pulmonary disease (COPD) in the new General Medical Services (GMS) contract for UK general practitioners (GPs) [1]. This has led to GPs either developing in-house spirometry, accessing hospital-based open access spirometry services, or trialling a mobile spirometry service [2]. Others have shown that each of these systems is feasible but that results obtained from one type of service are not always comparable with those obtained in another $[3,4]$. The National Institute for Clinical Excellence (NICE) guideline on the management of patients with COPD [5] also emphasises the importance of spirometry in general practice in order to confirm the diagnosis.

We set out to answer the question: in primary care, patients with which diagnoses or suspected diagnoses are referred for spirometry, and with what results?

\section{Methods}

We reviewed 200 consecutive patient referrals to an Open Access spirometry service at Charing Cross Hospital, London, from 10 local general practices. Until the launch of a new Community Respiratory Assessment Unit, the service was available without an appointment every Wednesday morning. Request forms were completed by the GP and sent to the laboratory with the patient; the forms require the GP to state the suspected or actual diagnoses. Results are interpreted by a consultant respiratory physician and reports are sent to the GP the same day. The request form, spirometry test result, and consultant report, were reviewed for each of the 200 patients.

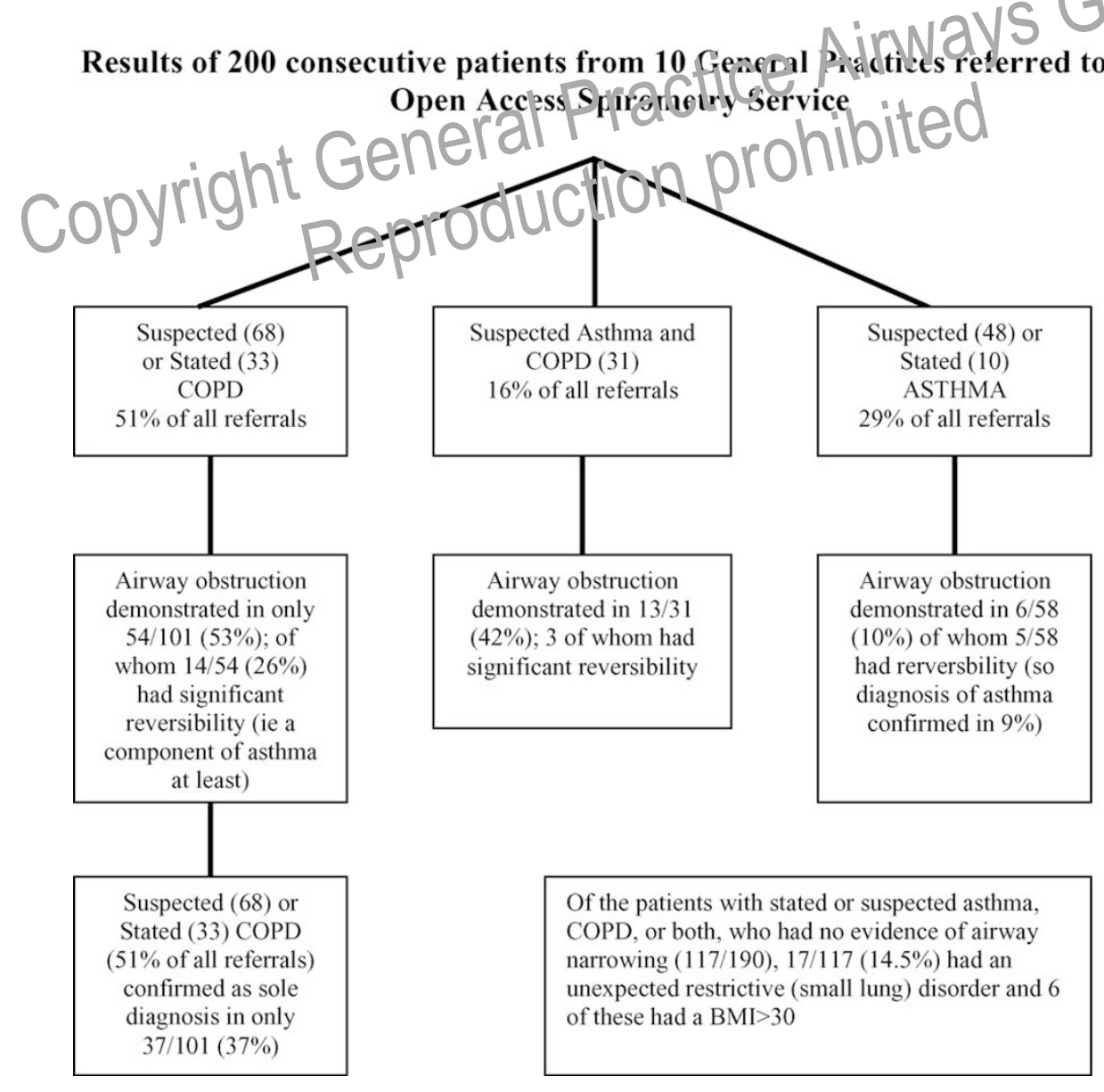

Figure 1 Types of patients referred to the open access spirometry service, and outcomes. 


\section{Results}

The stated and suspected diagnosis, and outcomes, are listed in Figure 1. Fifty-one percent of all referrals were with suspected or stated COPD but airway obstruction was only demonstrated in 54/101 $(53 \%)$ cases. Fourteen of these 54 patients $(26 \%)$ had reversibility of a degree (improvement in $\mathrm{FEV}_{1}<400 \mathrm{mls}$ after use of a broncochdilator) suggesting that asthma was an additional component, at least. On the basis of lack of reversibility or the appearance of pressure-dependent airway collapse on the flow volume curve, consultants reported that COPD was confirmed as the sole diagnosis in only $37 / 101$ cases (37\%). Asthma was the suspected or stated diagnosis in $29 \%$ of all referrals and airway obstruction was demonstrated in six out of 58 of those patients $(10 \%)$. However, reversibility was only demonstrated in five of the 58 patients.

117 patients were referred with stated or suspected asthma or COPD or both, but had no evidence of airway narrowing on testing. 17 out of these 117 patients $(14.5 \%)$ had an unexpected small lung (restrictive) disorder and six of these patients had a body mass index (BMI) of more than 30 , suggesting that obesity may be the cause for the small lung disorder.

\section{Discussion}

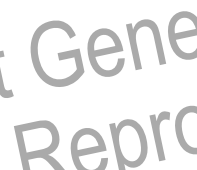

Primary care physicians (GPs) are being encouraged to perform spirometry in order to confirm the diagnosis of COPD, and their usage of an Open Access spirometry service suggests that this is correct - for without it mistaken diagnoses of COPD would appear to be likely. COPD is likely to be confused with both asthma and small lung defects, and some of the latter are due to a lack of recognition of obesity as a cause of breathlessness.

This study was undertaken in only one part of the UK, and the data regarding GPs' use of open access spirometry may suffer from having been undertaken in only one area. However, since our study was completed, there has been a further report on the use of spirometry and the correctness of diagnosis of COPD in general practice [6]. In that study, of 125 patients who were re-evaluated having previously been diagnosed with COPD, only 61 had spirometric confirmation, whilst 25 had reversible obstruction, 34 had normal spirometry, and five had restrictive spirometry.

If we set our study in the larger context, eight million people in the UK have lung disease, and respiratory disorders are the commonest reason for a patient to visit their GP [7]. In one study, almost a third of the population of England and Wales consulted their GP for a respiratory condition at least once during a year. Admission rates to hospital for just one lung disease, COPD, have increased by $50 \%$ over the last nine years [8]. The magnitude of the problem would thus seem to merit a structured approach to diagnosis and accurate assessment of severity. In a study of 153 patients admitted to an internal medicine service in a US hospital, airway obstruction was shown to be common in hospitalised patients, and usually undiagnosed and untreated [9]. A similar failure to make optimal use of spirometry has been noted in other countries [10]. One problem is that trainees report a lack of confidence in their ability to interpret results [11].

In UK primary care, the new GMS contract has included as a quality indicator the recording of the percentage of all patients with COPD where the diagnosis has been confirmed by spirometry [1]. This and other factors (including a quality indicator for regular review of those with asthma) has led to a resurgence of interest in the inangement of respiratory illness, with more Cls either purchasing spiromete for use within their own surgery or recluesting open acitess facilities in secondary care. As nuir stici has shown, spirometry can be us eivil in this context, for misdiagnoses are likely to have been common in those referred to our service if spirometry had not been undertaken. Our survey also suggests that referral of patients with presumed or suspected asthma was not particularly helpful, either because these patients did not have asthma, or because it was quiescent at the time of referral, or because they were on treatment that was fully controlling it. The diagnosis of asthma would therefore be better confirmed, in adults at least, by serial measurement of peak flow recording either during surgery visits, following a trial of therapy, or by patients in their own home - the approach recommended in the British guideline on the management of asthma [12].

Implementing recommendations regarding the use of spirometry clearly involves a number of steps, including access to equipment, appropriate training in the use of the equipment, and in interpretation of the results. Courses are available to teach these skills, such as those run by the National Respiratory Training Centre in the UK (part of Education for Health) and specific web-based materials are available, for example www.spirxpert.com [13]. However, practitioners have to see spirometry as a useful tool if they are to be motivated for training in its use. 
UK experience with the GMS contract suggests that financial reward can act as a catalyst for change.

\section{References}

[1] UK GP General Medical Services Contract, Department of Health (www.dh.gov.uk) accessed 22 June 2005.

[2] Jones R, Whittaker M, Hanney K, Shackell B. A pilot study of a mobile spirometry service in primary care. Prim Care Resp J 2005;14:169-71.

[3] Akhtar R, Wilson A. A comparison of spirometry in general practice and a pulmonary function laboratory. Prim Care Resp J 2005;14(4):215-20.

[4] Schermer TR, Jacobs JE, Shavannes EH, Hartman J, Folgering HT, Bottema BJ, van Weel C. Validity of spirometric testing in a general practice population of patients with chronic obstructive pulmonary disease (COPD). Thorax 2003;58:861-6.

[5] National Clinical Guideline on management of chronic obstructive pulmonary disease in adults in primary and secondary care. Chronic Obstructive Pulmonary Disease. Thorax 2004;59(Suppl 1):1-232.
[6] Bolton CE, lonescu AA, Edwards PH, Faulkner TA, Edwards CM, Shale DJ. Obtaining a correct diagnosis of COPD in general practice. Respir Med 2005;99:493-500.

[7] British Thoracic Society, The Burden of Lung Disease report, published 2001. pages 1-42.

[8] The Lung and Asthma Information Agency (LAIA) Admissions for Chronic Obstructive Pulmonary Diseases England 1991-2001. (www.laia.ac.uk. Accessed 22 June 2005).

[9] Zaas D, Wise R, Wiener C. Airways obstruction is common but unsuspected in patients admitted to a general medical service. Chest 2004;125:106-11.

[10] Fauzi AR. Knowledge and practice of medial doctors in chronic obstructive pulmonary disease: a preliminary survey from a state hospital. Med J Malaysia 2003;58:205-12.

[11] Wickstrom GC, Kaolar MM, Keyserling TC, Kelley DK, Xie SX, Bognar BA, Lewis CL, Dupre CT. Confidence of graduating internal medicine residents to perform ambulatory procedures. J Gen Intern Med 2000;15:361-5.

[12] British Thoracic Society/Scottish Intercollegiate Guidelines Network. British Guideline on the Management of Asthma. Thorax 2003;58(Suppl 1):1-94.

[13] Quanjer P, van den Aardweg J, Bottema BJAM, et al., Become an Expert in Spirometry. Available on line at http://www.spirxpert.com (Accessed 4th October 2005).

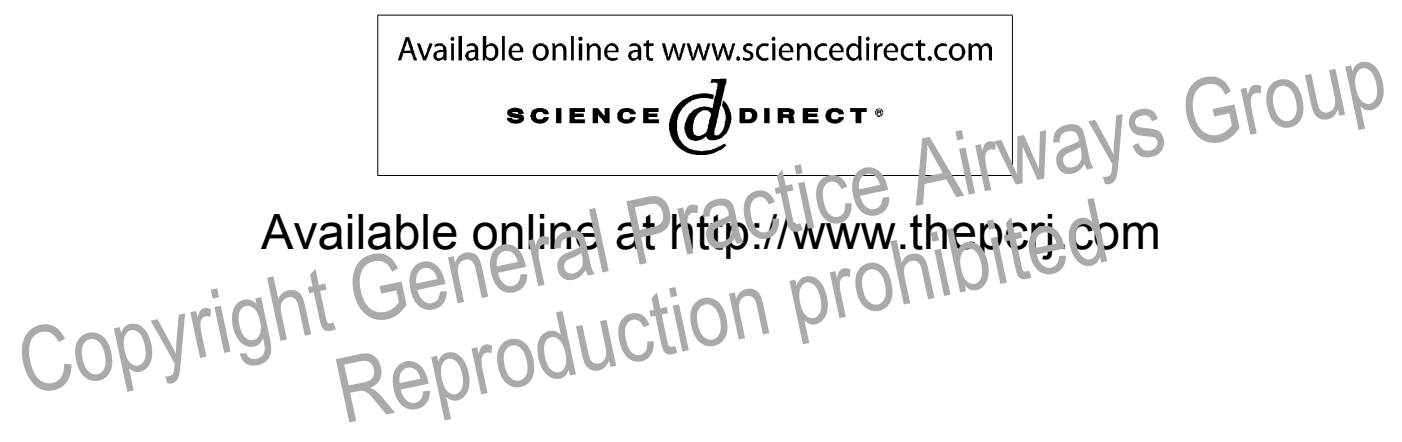

